\title{
Islanded Operation of Microgrids with Inverter Connected Renewable Energy Resources
}

\author{
H. R. Pota ${ }^{*}$ M. J. Hossain ${ }^{* *}$ M. A. Mahmud ${ }^{* * *}$ R. Gadh Ma** $^{* *}$ \\ R. C. Bansal ${ }^{\dagger}$ \\ * School of Engineering and Information Technology (SEIT), The University \\ of New South Wales, Canberra, ACT 2600, Australia (h.pota@adfa.edu.au). \\ ${ }^{* *}$ Griffith School of Engineering, Griffith University, Gold Coast Campus, \\ Gold Coast, QLD 4222, Australia (j.hossain@griffith.edu.au). \\ *** Faculty of Engineering \& Industrial Sciences, Swinburne University of \\ Technology, Hawthorn, VIC 3122, Australia (mmahmud@swin.edu.au). \\ **** Department of Mechanical and Aerospace Engineering, The University \\ of California, Los Angeles, CA 90095, USA \\ ${ }^{\dagger}$ Department of Electrical, Electronic, and Computer Engineering, \\ University of Pretoria, South Africa
}

\begin{abstract}
This paper contains a control scheme for power sharing in islanded microgrids with invertersourced distributed energy resources that combines robust control and droop control. As the load within the microgrid changes, the inverter-sourced generators share the change in the load; this paper shows that the uncontrolled load sharing among the generators will be arbitrary and methods such as droop control achieve a regulated change. This paper includes a background on control schemes for power sharing and highlights the difficulty in exact reactive power sharing. The performance of the proposed controller is demonstrated using a test microgrid system.
\end{abstract}

Keywords: Microgrid, power balance, energy storage, renewable energy source

\section{INTRODUCTION}

Interconnection of microgrids is a practical way to achieve higher utilisation of renewable energy, reduce transmission losses, lower infrastructure capital investment, and achieve higher reliability of electricity supply (Lasseter, 2002, 2011). Experimental microgrids have been developed to test the basic ideas (Lasseter et al., 2011).

Energy sources in microgrids are likely to be renewable resources interconnected via voltage source converters (VSC). Most VSCs are controlled to output a set voltage magnitude and phase. This is in contrast to synchronous machine based grid operation where the voltage magnitude and the rate-ofchange of the generator angle (frequency) is set as a result of the interaction between the generation and load dynamics. As shown in the following if the VSC output voltage magnitude and angle are not controlled the system operation will result in unplanned generation levels and voltage profile in microgrids (Lasseter, 2011).

There exists rich literature in power sharing amongst parallel inverters (De Brabandere et al., 2007). It is common to refer to real power sharing droop control as frequency droop control (De Brabandere et al., 2007). The frequency droop control is so designed that the output of each inverter has a different frequency. In power systems operation it is assumed that there exists a steady-state frequency and thus each inverter output cannot be at different frequencies. In this paper the frequency droop control is stated in terms of the output angle of the inverters. Present day fast acting inverters are able to quickly change the phase of the output voltage and it is more meaningful to specify the power sharing control as a rate-of-change of angle droop control.

Recent survey papers (Guerrero et al., 2013a,b) contain useful background information on microgrids and a rich bibliography. A review of experimental microgrids is covered in (Lidula and Rajapakse, 2011). The sharing of the reactive power in a microgrid is complicated owing to the fact that the conventional method of sharing based on the generator terminal voltage does not work in microgrids (Johnson et al., 2011). Some solutions for reactive power sharing from the literature are discussed in this paper.

Most of the microgrid literature treats voltage sources behind the inverters as ideal (Lasseter, 2002, 2011; De Brabandere et al., 2007). This assumption is perfectly valid for the research in power sharing amongst parallel connected inverters (De Brabandere et al., 2007) but it needs extension when the ideal voltage sources are replaced with renewable energy resources. The presentation in this paper is with an emphasis on microgrids from a power systems point-of-view. It is clearly brought out that the rate-of-change of angle droop requires a change in the input power and there needs to be another controller to achieve this objective. In the next section an analysis is presented which brings out the essential elements in control algorithms for power sharing amongst renewable resources in microgrids.

\section{POWER SHARING WITHOUT CONTROL}

Analysis of a two-source microgird is instructive to get a basic understanding of the microgrid operation and the research 
problems. Most renewable energy sources are connected to the microgrid using inverters. The inverter connected energy generation can be modelled as a voltage source with controllable voltage magnitude and phase (Coelho et al., 2002; Johnson et al., 2011). Fig. 1 shows a two voltage-source microgrid with one resistive load. The voltage source values $V_{1}, \delta_{1}, V_{2}$, and $\delta_{2}$ can be independently controlled. In this paper it is assumed that the inverters are fast and there are no stator transients.

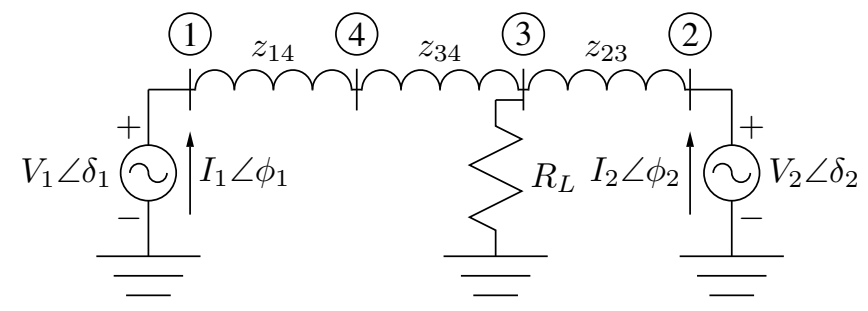

Fig. 1. A Simple Microgrid

The transmission line parameters for the microgrid in Figure 1 are: $z_{14}=0.0+\jmath 0.05 \mathrm{pu}, z_{34}=0.0+\jmath 0.2 \mathrm{pu}$, and $z_{23}=0.0+$ j0.05 pu. Bus 1 is a PV bus: $P_{1}^{0}=0.5 \mathrm{pu}, V_{1}=1 \mathrm{pu}$, bus 2 is a slack bus: $V_{2}=1 \mathrm{pu}, \delta_{2}^{0}=0^{\circ}$, and the load resistor is: $R_{L}=1 \mathrm{pu}$; the initial values of $\delta_{1}, V_{3}$, and $\delta_{3}$ are obtained using a load-flow solution and the values are: $\delta_{1}^{0}=5.7663^{\circ}$, $V_{3}=0.9984 \mathrm{pu}, \delta_{3}^{0}=-1.4258^{\circ}$.

To see the effect of the load change, the load resistor $R_{L}$ is changed to $0.5 \mathrm{pu}$. Let the voltage sources hold the voltage magnitude and phase values at the pre-change values. For these values the real and reactive powers supplied by the two voltage sources are: $P_{1}=0.6616 \mathrm{pu}, P_{2}=1.3190 \mathrm{pu}$, $Q_{1}=0.0740 \mathrm{pu}, Q_{2}=0.1247 \mathrm{pu}$, and $P_{R_{L}}^{0}=1.9805 \mathrm{pu}$. This means $\Delta P_{1}=P_{1}-P_{1}^{0}=0.1616 \mathrm{pu}$ and $\Delta P_{2}=$ $P_{2}-P_{2}^{0}=0.8221 \mathrm{pu}$; from these values it can be seen that the extra load is not evenly divided between the two voltage sources. It is desirable to distribute the change in the load amongst generators depending on their ratings or some other consideration. We need a method to be able to perform this load distribution automatically. This can be achieved by a masterslave control or what is normally called droop control after the governor control of synchronous machines.

\section{POWER SHARING WITH CONTROL}

The control methods used for power sharing can be broadly classified into two categories. The first category is of masterslave control methods that have been developed for load sharing by parallel connection of uninterrupted power supplies. The second category is of droop control methods which are more suited to load sharing among distributed energy resources (DERs) in microgrids. A summary of both the categories is presented next.

\subsection{Master-Slave Control}

Many power sharing methods for microgrids have their basis in load-sharing among parallel interrupted power supplies (UPS) to supply a critical load. Most of the UPS load sharing schemes that are useful for microgrids can be covered under the masterslave configuration shown in Figure 2.

For an automatic load sharing, one master distributed energy resource (DER) is designated, and all other DERs are put in the

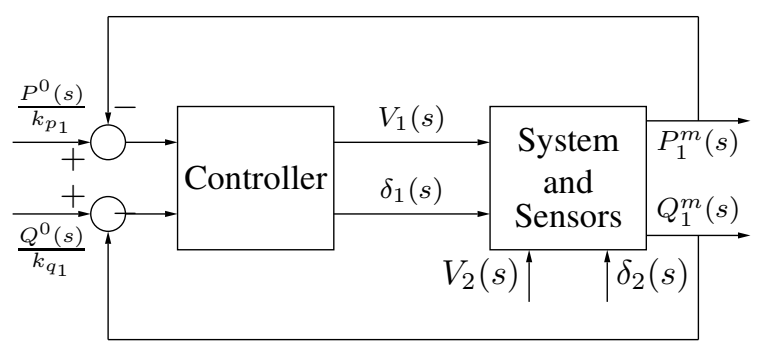

Fig. 2. Master-slave configuration for power sharing

slave mode. When the load changes, the output of each DER will change as shown in the previous section. In general, the change in the output of DERs will not be in any desired way, and to have a controlled change this master-slave structure is used. Let the new output of the master controller be $P^{0}$ and $Q^{0}$, then the master controller communicates the set-points to all other DERs as:

$$
\begin{aligned}
& P_{i}^{0}=k_{p_{i}} P^{0} \\
& Q_{i}^{0}=k_{q_{i}} Q^{0}
\end{aligned}
$$

where $k_{p_{i}}$ and $k_{q_{i}}$ are chosen for a controlled distribution of change in the load.

The above described master-slave structure has many variations and they all require a communication link to work (Vandoorn et al., 2013). Next we look at load sharing methods which do not require a communication link.

\subsection{Droop Control}

In this section the droop control method for sharing power due to load changes is presented. For inverter sourced generation the phase of the voltage can be advanced according to a control law which appears like a droop. For example, angle $\delta_{i}$ is reduced if the generator supplies more than the reference load and viceverse. The droop controllers (shown in Figures 3 and 4) are $(i=1,2)$ :

and

$$
\dot{\delta}_{i}=-k_{p_{i}}\left(P_{m_{i}}-P_{i}^{0}\right)
$$

$$
\Delta V_{i}=-k_{q_{i}}\left(Q_{m_{i}}-Q_{i}^{0}\right) \text {. }
$$

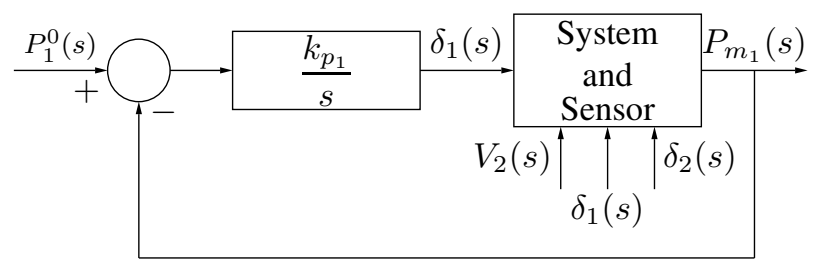

Fig. 3. Droop control for real power sharing

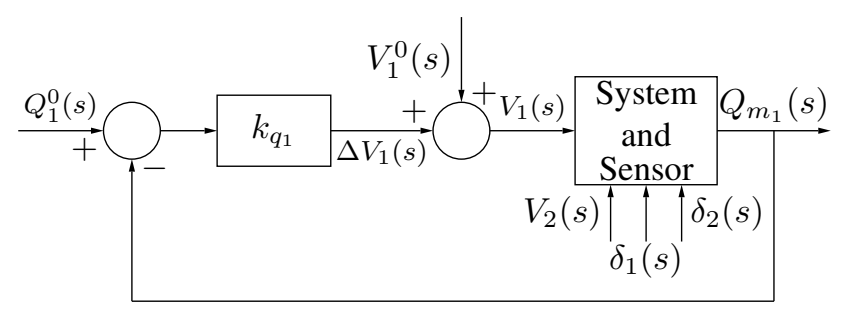

Fig. 4. Droop control for reactive power sharing

For a stable operation it is necessary that the real and reactive powers are such that $\dot{\delta}_{1}-\dot{\delta}_{2}=0$. This guarantees that using 
the droop control law (3), the real power is shared in inverse proportion to $k_{p_{i}}$. In steady-state the change in the system frequency is $\dot{\delta}_{1}=\dot{\delta}_{2}=\Delta \omega$. The $\mathrm{QV}$ droop control in (4) does share the reactive power change but it does not share it proportionately and it depends on transmission line parameters. Next we present a two-bus system analysis with a view to designing a droop scheme to share the change in the reactive power proportionately.

\section{Power Relationships for Two-bus System}

The complex power entering a node can be written as:

$$
S_{i}=P_{i}+\jmath Q_{i}=V_{i} \angle \delta_{i} \times I_{i} \angle-\phi_{i}, \quad i=1,2 .
$$

Also

$$
I_{i} \angle \phi_{i}=\sum_{j=1}^{2} \operatorname{Yred}_{i j} V_{j} \angle \delta_{j}
$$

where Yred $=Y_{11}-Y_{12} Y_{22}^{-1} Y_{21}$. The submatrices $Y_{i j}$ are made from YBus by grouping both the voltage-source terms in ' 1 ' and the load bus as ' 2 '. Let $\operatorname{Yred}_{i j}=G_{i j}+\jmath B_{i j}$, define $\delta_{i j}=\delta_{i}-\delta_{j}$, and then putting (5) and (6) together, we get

$$
\begin{aligned}
P_{i} & =\sum_{j=1}^{2} V_{i} V_{j}\left(G_{i j} \cos \delta_{i j}+B_{i j} \sin \delta_{i j}\right) \\
Q_{i} & =\sum_{j=1}^{2} V_{i} V_{j}\left(G_{i j} \sin \delta_{i j}-B_{i j} \cos \delta_{i j}\right)
\end{aligned}
$$

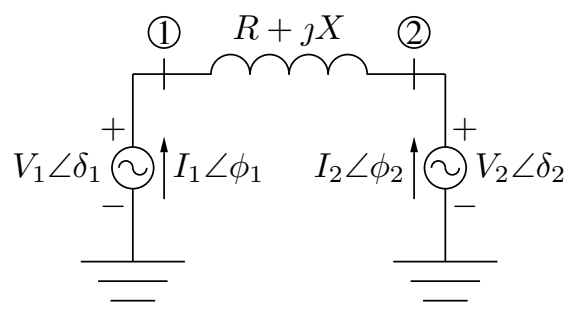

Fig. 5. A two-bus system

The above power relationships (7) and (8) for a two-bus system shown in Figure 5 can be written as follows, with $B_{11}=B_{22}=$ $\frac{-X}{Z^{2}}, G_{11}=G_{22}=\frac{R}{Z^{2}}, B_{12}=B_{21}=\frac{X}{Z^{2}}, G_{12}=G_{21}=\frac{-R}{Z^{2}}$, and $Z=\sqrt{R^{2}+X^{2}}$ :

$$
\begin{aligned}
P_{1} & =\frac{V_{1}^{2} R}{Z^{2}}+V_{1} V_{2}\left(-\frac{R}{Z^{2}} \cos \delta_{12}+\frac{X}{Z^{2}} \sin \delta_{12}\right) \\
Q_{1} & =\frac{V_{1}^{2} X}{Z^{2}}+V_{1} V_{2}\left(-\frac{R}{Z^{2}} \sin \delta_{12}-\frac{X}{Z^{2}} \cos \delta_{12}\right) \\
Q_{2} & =\frac{V_{2}^{2} X}{Z^{2}}+V_{2} V_{1}\left(-\frac{R}{Z^{2}} \sin \delta_{21}-\frac{X}{Z^{2}} \cos \delta_{21}\right) \\
Q_{1}-Q_{2} & =\left(V_{1}^{2}-V_{2}^{2}\right) \frac{X}{Z^{2}}-\frac{2 V_{1} V_{2} R \sin \delta_{12}}{Z^{2}}
\end{aligned}
$$

The above power relationships have a simplification for some commonly used transmission lines as shown in Table 1.

Table 1. Power Relationships for Special Cases

\begin{tabular}{|c|c|c|}
\hline & $X \gg R$ & $R \gg X$ \\
\hline$P_{1}$ & $\frac{V_{1} V_{2}}{X} \sin \delta_{12}$ & $\frac{V_{1}\left(V_{1}-V_{2}\right)}{R}$ \\
\hline$Q_{1}$ & $\frac{V_{1}\left(V_{1}-V_{2}\right)}{X}$ & $-\frac{V_{1} V_{2}}{R} \sin \delta_{12}$ \\
\hline
\end{tabular}

\section{REACTIVE POWER SHARING}

For a two-source microgrid with the droop control shown in Figure 1 , for a change in $\Delta Q_{3}$, the ratio of the change in $\Delta Q_{1}$ and $\Delta Q_{2}$ is given as follows:

$$
\frac{\Delta Q_{1}}{\Delta Q_{2}}=\frac{-V_{1}^{0} B_{13} \cos \delta_{13}^{0}\left(1-k_{q_{2}}\left(V_{3}^{0} B_{23} \cos \delta_{23}^{0}+2 V_{2}^{0} B_{22}\right)\right)}{-V_{2}^{0} B_{23} \cos \delta_{23}^{0}\left(1-k_{q_{1}}\left(V_{3}^{0} B_{13} \cos \delta_{13}^{0}+2 V_{1}^{0} B_{11}\right)\right)}
$$

Expression (13) clearly indicates that the sharing of reactive power using a simple droop will be in the ratio of admittances. This is a fundamental limitation in the use of QV droop control. In the following we discuss how to overcome this limitation and provide proportional reactive power sharing.

In ( $\mathrm{He}$ and $\mathrm{Li}, 2011$ ) virtual impedance concept for reactive power sharing and resonant filters for harmonic current support is proposed. The control scheme (He and Li, 2011, Fig. 11) shows how the measured current is used with an "impedance" block to synthesise virtual impedance.

In (Etemadi et al., 2012a,b) the design of decentralised robust controllers for multi-DER microgrids is presented. Each DER is a subsystem with a fully controllable voltage source and the control objective being the magnitude and angle of the voltage at the PCC. The PCC voltage settings are communicated from a central power management system using power flow analysis.

In (Zhong, 2013) a robust droop controller is presented for a predominantly resistive network where reactive power is controlled by varying the phase difference and the real power by voltage magnitude. A proportionate sharing is achieved much like (17) introduced in (Johnson et al., 2011).

The difficulty with exact reactive power sharing as compared to real power sharing amongst multi-DER microgrids is that it is difficult to use an integral control with reactive power sharing. Let us look at the droop control equations (3)-(4), the system reaches equilibrium only when all $\dot{\delta}_{i}$ are equal but the same system has stable operation for multiple combinations of $\Delta V_{i}$. A proportionate reactive power sharing can be achieved only when the control algorithm can guarantee equal values of all $\Delta V_{i}$ at the new equilibrium.

It is possible but a very difficult problem to design control algorithms to ensure

$$
\Delta V_{1}=\Delta V_{2}=\cdots=\Delta V_{N}
$$

One way to achieve equal $\Delta V_{i}$ is to have an integral control of the form:

$$
\Delta V_{i}=\int\left(\Delta V_{i}-\Delta V_{\text {com }}\right) d t
$$

where $\Delta V_{i}=-k_{q_{i}}\left(Q_{m_{i}}-Q_{i}^{0}\right)$ and $\Delta V_{\text {com }}$ has to be the change in the voltage at a pre-chosen common point in the microgrid and this scheme needs communication amongst the inverters or the DERs. A schematic of this scheme is shown in Figure 6.

In (Sao and Lehn, 2005) the control law is:

$$
\begin{aligned}
V_{i} & =V_{i}^{0}+k_{q i_{i}} \int\left(V_{\text {ref }_{i}}-V_{\text {com }}\right) d t \\
V_{\text {ref }_{i}} & =V_{i}^{0}-D_{q_{i}} Q_{i} .
\end{aligned}
$$

In (Johnson et al., 2011) a proportional term is added to the above control law (15)-(16): 


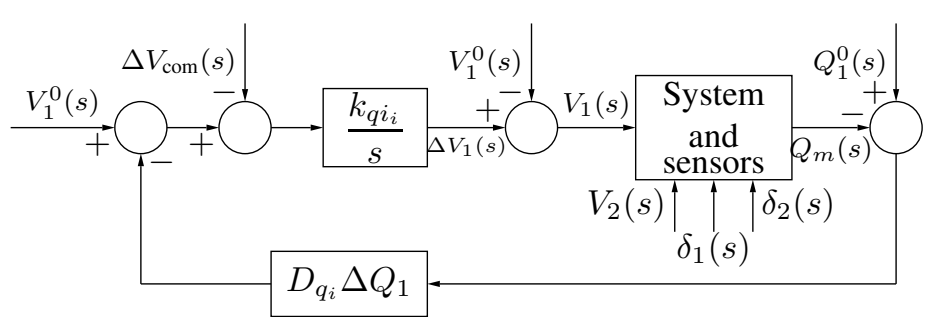

Fig. 6. Reactive Power Sharing Integral Control

$$
\begin{aligned}
V_{i} & =V_{i}^{0}+k_{q p_{i}}\left(V_{\operatorname{ref}_{i}}-V_{\text {com }}\right)+k_{q i_{i}} \int\left(V_{\operatorname{ref}_{i}}-V_{\mathrm{com}}\right) d t \\
V_{\operatorname{ref}_{i}} & =V_{i}^{0}-D_{q_{i}} Q_{i} .
\end{aligned}
$$

In the two-source microgrid considered in this paper $V_{\text {com }}=$ $V_{3}$.

When the system is stable, the argument of the integral in (17) should be zero, thus:

$$
V_{i}^{0}-D_{q_{i}} Q_{i}=V_{\text {com }}
$$

If voltages $V_{i}^{0}$ are the same then the reactive power is shared inversely proportional to $D_{q_{i}}$. Moreover the voltage change for $V_{\text {com }}$ will depend on the values of $D_{q_{i}}$. For small changes in $V_{\text {com }}$, constants $D_{q_{i}}$ must be small. The constants $k_{q i_{i}}$ determine the speed of response.

\section{CONTROL FOR MICROGRIDS WITH DER}

For DERs in microgrids there are different ways to choose the reference values, $P_{i}^{0}$ and $Q_{i}^{0}$, the steady-state real and reactive power output. In this paper the values prior to load change are used as the reference. In (Erickson et al., 2011) the DC link voltage in a PV system is used to set the reference real power. In (Chiang and Chang, 2001) a virtual impedance scheme is introduced to achieve (a) a balance in sharing the reactive power sharing, and (b) harmonic current sharing, amongst many voltage-sources. Nonlinear loads have to be supplied with harmonic currents thus there is a need to share the required harmonic currents equally amongst various voltage-sources. In (De Brabandere et al., 2007) a modified active and reactive power $P^{\prime}$ and $Q^{\prime}$ are proposed for control. This paper (De Brabandere et al., 2007) also discusses the use of virtual impedance for droop control. Future research needs to consider the dynamics of the energy resources along with the sensor dynamics for a proper design of microgrid droop controllers.

In (Kamel et al., 2013) a wind generator is combined with a storage device to provide a smooth output power. The wind generator is modelled with its dynamic equations but the energy storage devices are modelled as ideal DC sources. Reference power output for the wind generator is obtained by using short term predictions of wind speeds and pitch angle control. Fuzzy control is employed to control the pitch angle.

Robust control methods for controlling PV Solar (Mahmud et al., 2012) and wind generation (Hossain et al., 2013) have been proposed for transmission and distribution systems (Roy et al., 2013). In this paper these robust control algorithms are extended to work in the microgrid framework by appending an energy storage system and a droop controllers to each DER.

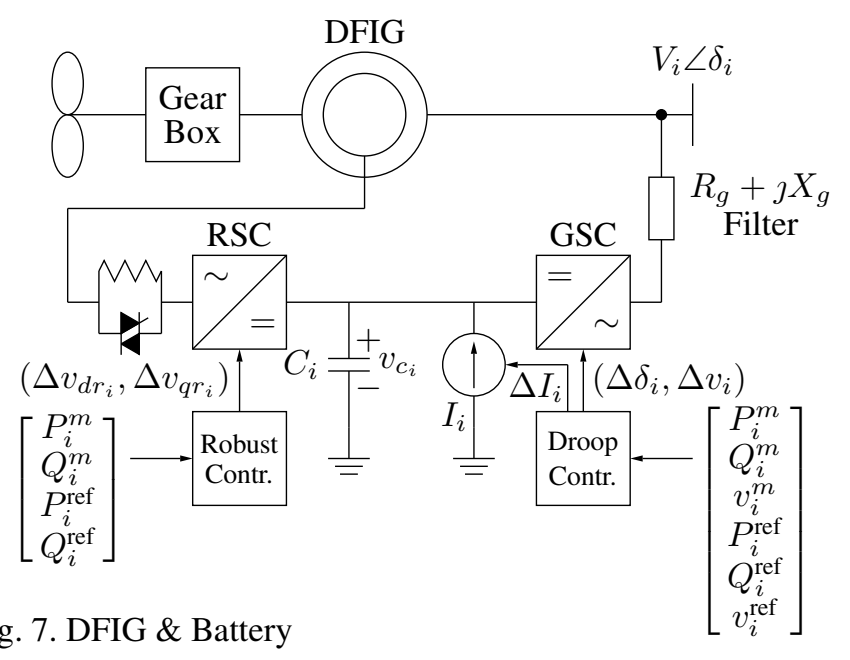

\subsection{DFIG and BES Control}

A doubly-fed induction generator (DFIG) with a battery energy storage (BES) is shown in Fig. 7 (represented as a current source). Droop control and energy-storage system control for the DFIG is achieved using the following control laws (superscript $m$ is used for measured values and $w$ for wind turbine, positive $\Delta I_{w}$ indicates battery charging):

$$
\begin{gathered}
\Delta I_{w}=-k_{I_{w}} \int\left(v_{d c}^{\mathrm{ref}}-v_{d c}^{\mathrm{m}}\right) d t \quad \text { (Battery Control) } \\
\Delta \delta_{w}=k_{\delta_{w}} \int\left(P_{w}^{\mathrm{ref}}-P_{w}^{\mathrm{m}}\right) d t \\
\Delta v_{w}=k_{q_{w}} \int\left(Q_{w}^{\mathrm{ref}}-Q_{w}^{\mathrm{m}}\right) d t
\end{gathered}
$$

In general $P_{w}^{\text {ref }}$ will be the predicted maximum power point based on wind speed and $P_{w}^{\text {ref }}$ and $Q_{w}^{\text {ref }}$ are controlled using the robust controllers in (Hossain et al., 2013). The desired active and reactive power is realized by controlling $i_{q r}$ and $i_{d r}$. To achieve the reference reactive power has a higher priority so the checker block checks the available capacity for $i_{q r}$ with respect to $i_{d r}$ for a converter with a 25 per cent rating of the DFIG. The battery, shown as a current source in Figure 7, charges or discharges to keep the capacitor voltage set to a reference value.

\subsection{PV and BES Control}

A PV unit with a battery (represented as a current source) is shown in Fig. 8. The control laws for the PV unit are given as (superscript $m$ is used for measured values and $p$ for the PV unit):

$$
\begin{gathered}
\Delta I_{p}=-k_{I_{p}} \int\left(v_{c}^{\mathrm{ref}}-v_{c}^{\mathrm{m}}\right) d t \quad \text { (Battery Control) } \\
\Delta \delta_{p}=k_{\delta_{p}} \int\left(P_{p}^{\mathrm{ref}}-P_{p}^{\mathrm{m}}\right) d t
\end{gathered}
$$

$v_{c}^{\text {ref }}$ is obtained from the maximum power point tracking (MPPT) algorithm. In general $P_{p}^{\text {ref }}$ will be the predicted maximum power point based on solar radiance and $P_{p}^{\text {ref }}$ and $Q_{p}^{\text {ref }}$ are achieved using the robust controllers in (Mahmud et al., 2012). In the voltage control mode of PV units, $P_{\mathrm{p}}$ and $Q_{\mathrm{p}}$ are achieved by the amplitude of the VSC terminal voltage. The error signals $P_{\mathrm{ref}_{p}}-P_{\mathrm{p}}$ and $Q_{\mathrm{ref}_{p}}-Q_{\mathrm{p}}$ are fed to the controller which produces $d$ - and $q$-axis components of the VSC current 


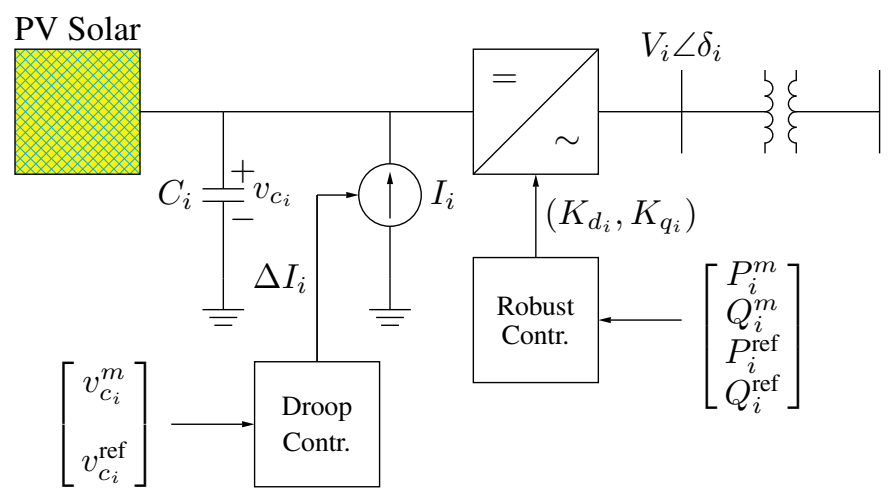

Fig. 8. PV \& Battery

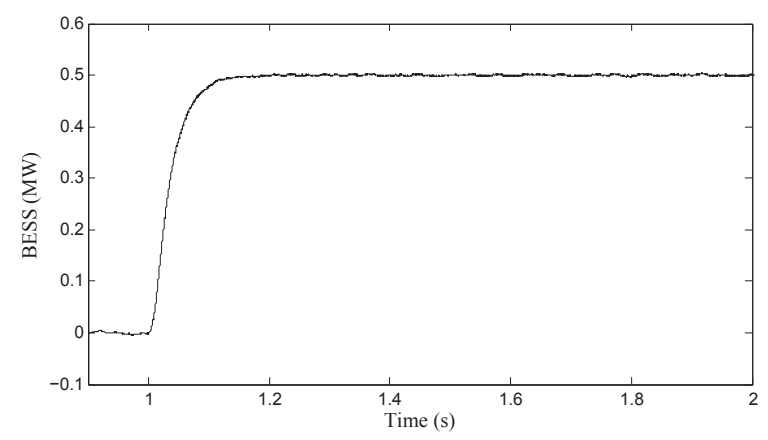

Fig. 9. Real power output of BES unit during islanding.

at their respective reference values which are again processed to get reference voltage components. The battery, shown as a current source in Fig. 8, charges or discharges to keep the capacitor voltage at $v_{d c}^{\text {ref }}$.

The values of the above mentioned parameters $k_{I_{w}}, k_{\delta_{w}}, k_{q_{w}}$, $k_{I_{p}}$ and $k_{\delta_{p}}$ are determined by minimizing an error integrating cost function which ensures a stable system with minimum steady-state errors. The cost function is given as

$$
J=\left[\sum_{t=t_{0}}^{t_{f}}\left(t-t_{0}\right) \cdot W \cdot|E|\right]
$$

where $t_{0}$ and $t_{f}$ are the starting and ending times for calculating control performance, $W$ is a weighting matrix and $E=\left[\Delta v_{d c_{w}}, \Delta P_{w}, \Delta Q_{w}, \Delta v_{d c_{p}}, \Delta P_{p}\right]$ is the absolute error matrix; $\Delta P$ and $\Delta Q$ represent the error between the real and reactive power references and measurements and $\Delta v_{d c}$ is the voltage deviation from its nominal value.

The performance of the designed controller during an islanded mode is discussed in the following section.

\section{CONTROLLER PERFORMANCE EVALUATION}

The test microgrid in (Katiraei et al., 2005) is used for controller performance evaluation. The system consists of three $13.8 \mathrm{kV}$ feeders which are connected to the grid through a $69 \mathrm{kV}$ radial line. The total load of the system is $7.3 \mathrm{MW}$ and 3.97 MVAr.

The PV unit is connected to the system via the VSC. The stator of the DFIG is connected directly to the grid and the rotor via a VSC. The rating of the PV unit is $3.0 \mathrm{MW}$ and the DFIG is $3.5 \mathrm{MW}$. Both the PV unit and the DFIG are connected to a battery energy storage system. The rating of

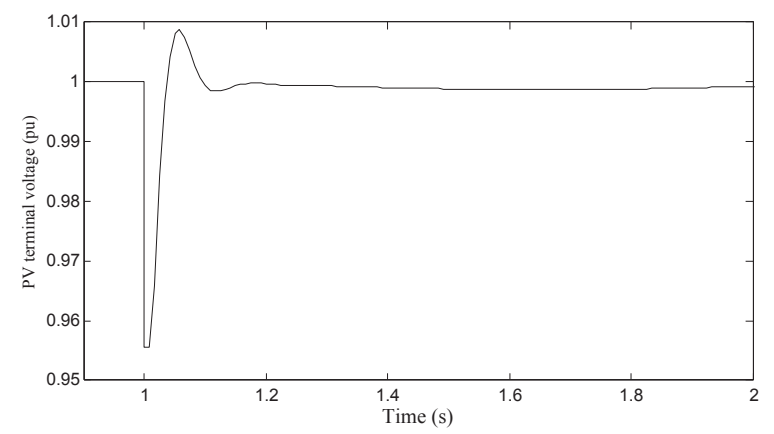

Fig. 10. Terminal voltage of PV unit during islanding.

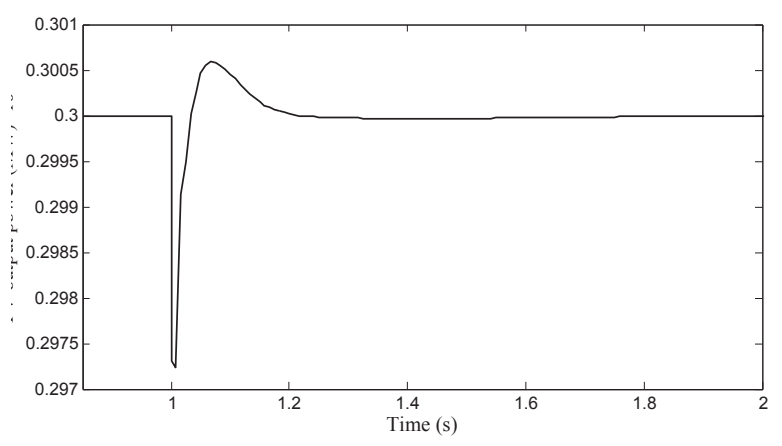

Fig. 11. Real power output of PV unit during islanding.

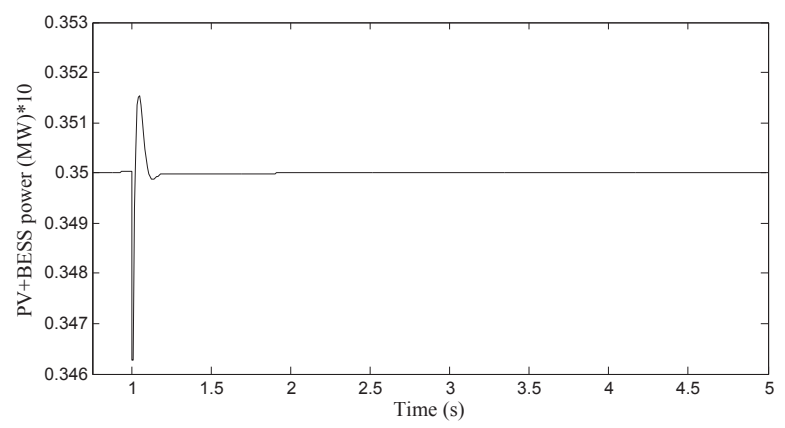

Fig. 12. Combined real power output of PV and BES units during islanding.

each battery is $0.6 \mathrm{MWh}$. The DC-link voltage is $1200 \mathrm{~V}$ and the capacitor is $10000 \mu \mathrm{F}$. Five-hundred and sixty-two $2.135 \mathrm{~V}$ lead-acid batteries are connected in series to get the desired voltage. Maximum charging or discharging current is $5 \mathrm{kA}$. Each distribution line is represented by lumped series RL branches. During the islanded mode the remaining balance of $1 \mathrm{MW}$ power is supplied by the BES.

The weighting matrix in (25) is chosen as $[0.5,1.0,1.0,0.5,1.0]$; the obtained control parameters for the wind turbines are $k_{I_{w}}=$ $13.25, k_{\delta_{w}}=8, k_{v_{w}}=20$ and for the PV unit are $k_{I_{p}}=$ $5, k_{\delta_{p}}=30$. Droop controllers are tuned first and then their dynamics are included in the robust controller design.

Initially the microgrid is working in a grid-connected mode and the performance of the designed controller is investigated for a pre-planned islanding. At $1 \mathrm{~s}$, an intentional islanding command is applied to the $69 \mathrm{kV}$ line breakers and the batteries are switched on so that they share the remaining balance of $1 \mathrm{MW}$ of power. Figures 9 and 10 show the real power output of the battery energy storage (BES). The wind generator and PV 
unit continue to operate at their optimum value. The real output power of the PV unit is shown in Fig. 11 the combined output power of the PV unit and BES is shown in Fig. 12.

Both the DER units control their reactive power to control the terminal voltage. The voltage disturbance associated with mode transition is eliminated by the voltage controller. Both the phase angle and magnitude of the controlled voltage are quickly modulated by the proposed controller in order to reject the voltage and power angle disturbances. The damping provided by the robust power sharing controller yields a well damped power sharing performance. From this study it is clear that the proposed controller can ensure stability and damped transient performance during switching from grid-connected to islanded mode.

\section{CONCLUSION}

For ideal inverter-connected voltage sources droop control can help in sharing real and reactive power. The control design is simple owing to the restricted sensor and controller dynamic interaction. The challenge is to include generation and load dynamics, with their controls, and guarantee stability of islanded microgrids. Energy storage systems can be used to support DERs to achieve robust control to maintain stability for large disturbances and droop control for effective power sharing.

\section{REFERENCES}

Chiang, S. and Chang, J. (2001). Parallel control of the UPS inverters with frequency-dependent droop scheme. In Power Electronics Specialists Conference, 2001. PESC. 2001 IEEE 32nd Annual, volume 2, 957-961.

Coelho, E., Cortizo, P., and Garcia, P. (2002). Small-signal stability for parallel-connected inverters in stand-alone ac supply systems. Industry Applications, IEEE Transactions on, 38(2), 533-542.

De Brabandere, K., Bolsens, B., Van den Keybus, J., Woyte, A., Driesen, J., and Belmans, R. (2007). A voltage and frequency droop control method for parallel inverters. Power Electronics, IEEE Transactions on, 22(4), 1107-1115.

Erickson, M., Jahns, T., and Lasseter, R. (2011). Comparison of PV inverter controller configurations for CERTS microgrid applications. In Energy Conversion Congress and Exposition (ECCE), 2011 IEEE, 659-666.

Etemadi, A., Davison, E., and Iravani, R. (2012a). A decentralized robust control strategy for multi-DER microgrids-Part I: Fundamental concepts. Power Delivery, IEEE Transactions on, 27(4), 1843-1853.

Etemadi, A., Davison, E., and Iravani, R. (2012b). A decentralized robust control strategy for multi-DER microgrids-Part II: Performance evaluation. Power Delivery, IEEE Transactions on, 27(4), 1854-1861.

Guerrero, J., Chandorkar, M., Lee, T., and Loh, P. (2013a). Advanced control architectures for intelligent microgridsPart I: Decentralized and hierarchical control. Industrial Electronics, IEEE Transactions on, 60(4), 1254-1262.

Guerrero, J., Loh, P.C., Lee, T.L., and Chandorkar, M. (2013b). Advanced control architectures for intelligent microgridsPart II: Power quality, energy storage, and ac/dc microgrids. Industrial Electronics, IEEE Transactions on, 60(4), 12631270 .

He, J. and Li, Y.W. (2011). Analysis, design, and implementation of virtual impedance for power electronics interfaced distributed generation. Industry Applications, IEEE Transactions on, 47(6), 2525-2538.

He, J. and Li, Y.W. (2012). An enhanced microgrid load demand sharing strategy. Power Electronics, IEEE Transactions on, 27(9), 3984-3995.

Hossain, M.J., Saha, T.K., Mithulananthan, N., and Pota, H.R. (2013). Control strategies for augmenting LVRT capability of DFIGs in interconnected power systems. IEEE Transactions on Industrial Electronics, 60(6), 2510 -2522.

Johnson, B., Davoudi, A., Chapman, P., and Sauer, P. (2011). A unified dynamic characterization framework for microgrid systems. Electric Power Components and Systems, 40(1), 93-111.

Kamel, R., Chaouachi, A., and Nagasaka, K. (2013). Three control strategies to improve the microgrid transient dynamic response during isolated mode: A comparative study. Industrial Electronics, IEEE Transactions on, 60(4), 1314-1322.

Katiraei, F., Iravani, M., and Lehn, P. (2005). Micro-grid autonomous operation during and subsequent to islanding process. Power Delivery, IEEE Transactions on, 20(1), 248257.

Lasseter, R. (2002). Microgrids. In Power Engineering Society Winter Meeting. IEEE, volume 1, 305-308.

Lasseter, R. (2011). Smart distribution: Coupled microgrids. Proceedings of the IEEE, 99(6), 1074-1082.

Lasseter, R., Eto, J., Schenkman, B., Stevens, J., Vollkommer, H., Klapp, D., Linton, E., Hurtado, H., and Roy, J. (2011). CERTS microgrid laboratory test bed. Power Delivery, IEEE Transactions on, 26(1), 325-332.

Li, Y.W. and Kao, C.N. (2009). An accurate power control strategy for power-electronics-interfaced distributed generation units operating in a low-voltage multibus microgrid. Power Electronics, IEEE Transactions on, 24(12), 2977-2988.

Lidula, N. and Rajapakse, A. (2011). Microgrids research: A review of experimental microgrids and test systems. Renewable and Sustainable Energy Reviews, 15(1), 186-202.

Mahmud, M.A., Pota, H.R., and Hossain, M.J. (2012). Dynamic stability of three-phase grid-connected photovoltaic system using zero dynamic design approach. IEEE Journal of Photovoltaics, 2(4), 564-571.

Roy, N.K., Pota, H.R., and Hossain, M.J. (2013). Reactive power management of distribution networks with wind generation for improving voltage stability. Renewable Energy, 58, 85-94.

Sao, C. and Lehn, P. (2005). Autonomous load sharing of voltage source converters. Power Delivery, IEEE Transactions on, 20(2), $100-1016$.

Tuladhar, A., Jin, H., Unger, T., and Mauch, K. (1997). Parallel operation of single phase inverter modules with no control interconnections. In Applied Power Electronics Conference and Exposition, 1997. APEC'97 Conference Proceedings 1997., Twelfth Annual, volume 1, 94-100.

Tuladhar, A., Jin, H., Unger, T., and Mauch, K. (2000). Control of parallel inverters in distributed AC power systems with consideration of line impedance effect. Industry Applications, IEEE Transactions on, 36(1), 131-138.

Vandoorn, T., Kooning, J.D., Meersman, B., and Vandevelde, L. (2013). Review of primary control strategies for islanded microgrids with power-electronic interfaces. Renewable and Sustainable Energy Reviews, 19(0), 613 - 628.

Zhong, Q.C. (2013). Robust droop controller for accurate proportional load sharing among inverters operated in parallel. Industrial Electronics, IEEE Trans. on, 60(4), 1281-1290. 